\title{
A investigação da diversidade biocultural no Norte de Minas Gerais e sua contribuição à justiça ambiental
}

\author{
The ethnoecological investigation of biocultural diversity in the North \\ of Minas Gerais and its contribution to environmental justice
}

Ana Paula Glinfskoi Thé ${ }^{1}$

\begin{abstract}
Resumo
Este artigo foi elaborado a partir de revisão bibliográfica de estudos em antropologia, etnoecologia e sociologia ambiental realizados no Norte de Minas Gerais e de experiências de campo entre comunidades vazanteiras e pescadoras do Médio Rio São Francisco. O objetivo é discutir a importância de pesquisas para a resolução de conflitos ambientais gerados pela implantação de Unidades de Conservação de Proteção Integral em territórios tradicionais. Ao abordar o conjunto de saberes ambientais produzidos por populações tradicionais em suas interações com a natureza, as etnociências permitem compreender melhor a história ambiental humana em determinados espaços e biomas, a formação de identidades e de territorialidades. A compreensão desses processos e elementos é fundamental para apoiar a garantia a direitos humanos e territoriais, combinada a um modelo de gestão compartilhada que possibilite acesso à natureza, seu uso sustentável e preservação.
\end{abstract}

Palavras-chaves: Identidades. Etnoecologia. Conflitos Ambientais. Gestão Compartilhada. Desenvolvimento.

\begin{abstract}
This article was elaborated from a bibliographical review of studies in anthropology, ethnoecology and environmental sociology carried out in the North of Minas Gerais and also, from field work experiences among the traditional fishery communities of the Middle São Francisco River. Its objective is to discuss the importance of research for the resolution of environmental conflicts generated by the implementation of Integral Protection Conservation Units in traditional territories. In addressing the set of environmental knowledge produced by traditional populations in their interactions with nature, ethnosciences allows a better understanding of human environmental history in certain spaces and biomes, the formation of identities and territorialities. Understanding these processes and elements is fundamental to support the guarantee of human and territorial rights, combined with a model of community management that allows access to nature, its sustainable use and protection.
\end{abstract}

Keywords: Identities. Ethnoecology. Environmental Conflicts. Co-Management. Development.

${ }^{1}$ Universidade Estadual de Montes Claros, Montes Claros, Minas Gerais. E-mail: anapgthe@gmail.com 


\section{Introdução}

Vários estudos sobre as populações tradicionais da zona semiárida brasileira demostram a relação entre o homem e a natureza e sua importância para a conservação dos recursos naturais em diferentes paisagens "sertanejas". Essas populações mostram longa experiência e familiaridade com ambiente e, por isso, são objeto da pesquisa interdisciplinar, visando a uma melhor compreensão da biodiversidade regional e a uma gestão sustentável dos diversos recursos ali presentes. No entanto, o projeto de desenvolvimento econômico hegemônico implementado no Brasil, principalmente a partir do ano de 1960, provocou a transformação total dessas paisagens. Baseado na silvicultura, na monocultura com irrigação em grande escala, na mineração, na siderurgia e no hidronegócio, entre outros exemplos de empreendimentos, esse modelo de desenvolvimento causou enormes impactos e conflitos ambientais, especialmente por recursos hídricos e pela terra, recursos dos quais as populações rurais tradicionais dependem (ZHOURI; LASCHEFSKI, 2010).

Aderida a essa concepção política de desenvolvimento, baseada no crescimento da economia por exportação de commodities e no incremento da indústria extrativa minerária, está em curso, como a principal política ambiental mitigadora dos impactos gerados, a criação de Unidades de Conservação de Proteção Integral (MMA, 2000). Diferentes tipos dessas Unidades de Conservação (como Parques
Nacionais e Estaduais, Estações Ecológicas, Reservas Naturais, entre outros) foram criados nos territórios de povos e comunidades tradicionais no Norte de Minas Gerais. Este artigo analisa a contribuição dos estudos sobre populações tradicionais, tanto para a conservação dos recursos biológicos como para a garantia de manutenção dos territórios tradicionais. Assim, espera-se que dialogue entre diversas disciplinas para o desenvolvimento de uma nova concepção de gestão ambiental e territorial no Brasil, mais democrática, participativa, com a equidade social baseada na sustentabilidade socioambiental (ANAYA; ESPIRITO-SANTO, 2018; THÉ et al., 2008).

\section{Povos, comunidades tradicionais e seus territórios no Norte de Minas Gerais}

O Norte de Minas apresenta grande diversidade de formações vegetais e paisagens (Figura 1), que são habitadas por diversas populações conhecidas e reconhecidas como tradicionais (Figura 2). Entre elas estão os geraizeiros, veredeiros, ribeirinhos, vazanteiros, caatingueiros, quilombolas e indígenas, entre outras. Há também os que se reconhecem apenas como sertanejos ou mesmo que pertencem a mais de um grupo, sendo quilombola e também vazanteiro, por exemplo (BRANDÃO, 2012; COSTA, 2006; DAYRELL, 1998). 
Figura 1 - Biomas do Estado de Minas Gerais

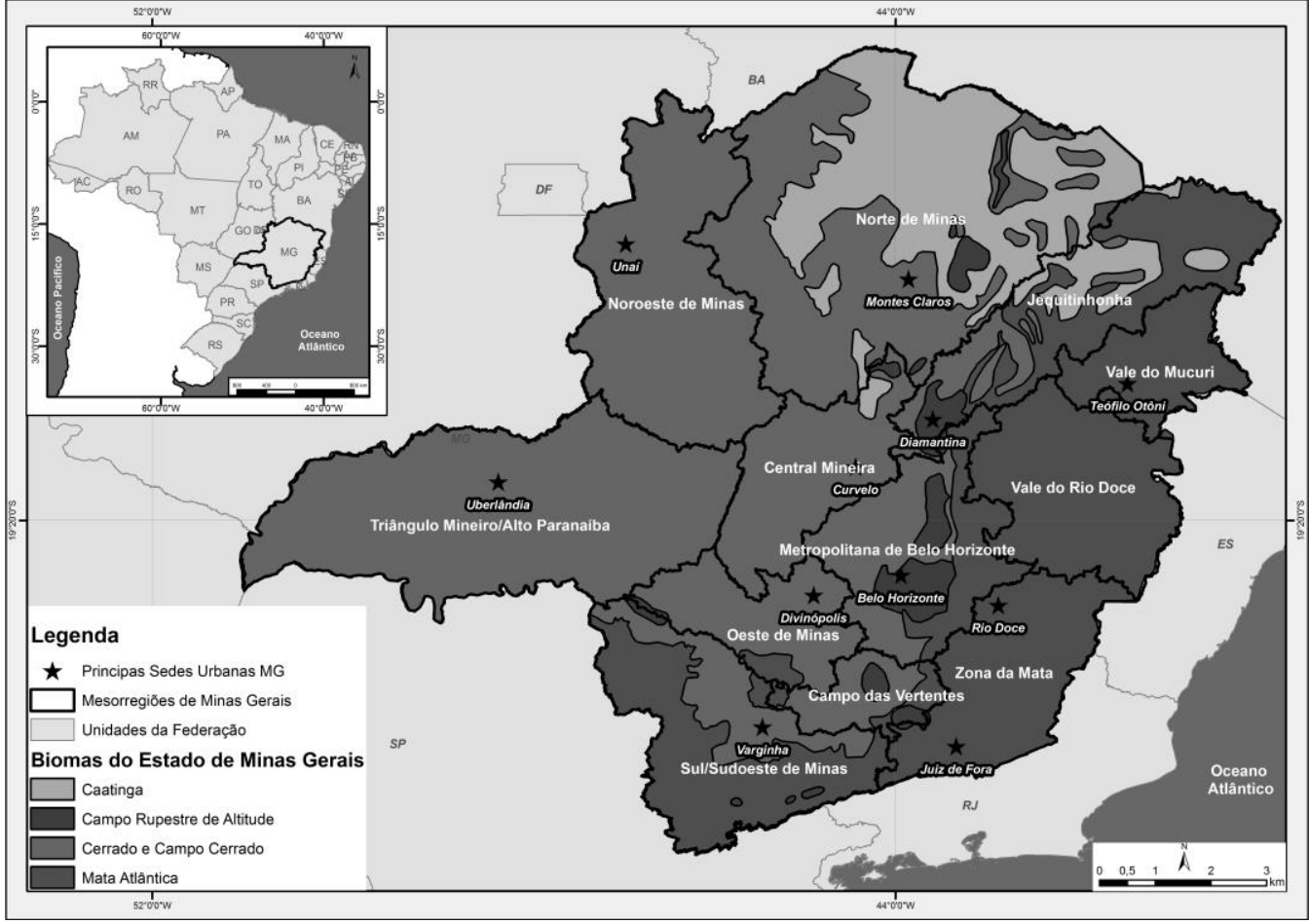

Fonte: Org. do Autor (2018).

Figura 2 - Localização das Comunidades Tradicionais do Norte de Minas Gerais

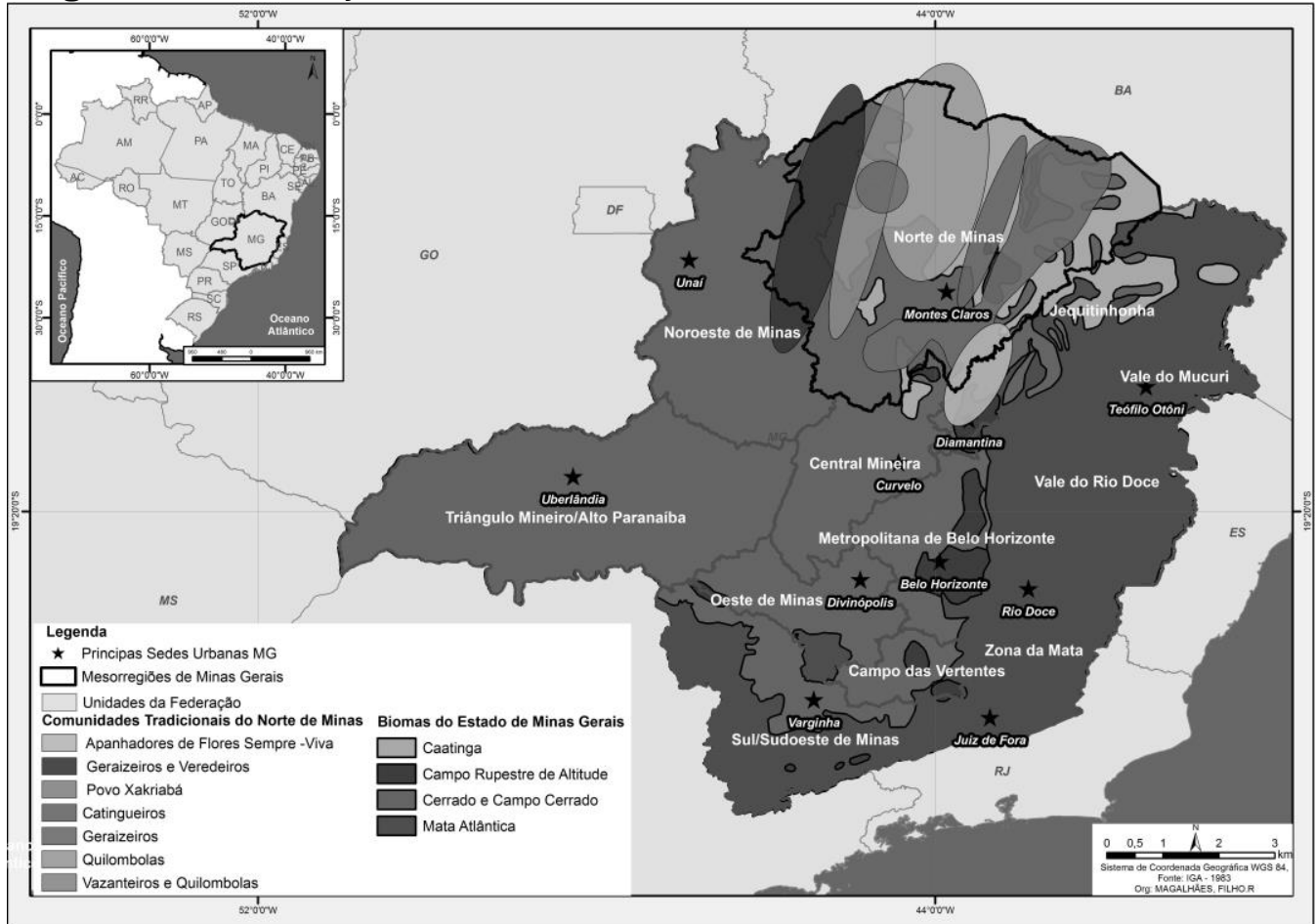

Fonte: Adaptado de Dayrell (2016). 
Assim, é permitido dizer que o sertão nortemineiro não é constituído de apenas uma identidade "biorregional" (SATO, 2005) mas de diversas identidades que se misturam e se completam formando uma paisagem diferenciada e complexa. Por paisagem entende-se uma forma de organização espacial resultante da interação entre os processos naturais e as atividades humanas (BERQUE, 2012; DIEGUES, 2000). Segundo Costa (2006), essa complexidade socioambiental, composta por diversas identidades e paisagens, é devida à geografia da região, que se encontra inserida numa área de transição entre o cerrado, a caatinga e a mata atlântica. Sobre esse espaço se desenvolveu a construção complexa dessas identidades coletivas por meio dos processos sócio-históricos dessas comunidades. Parte desses processos históricos podem ser vislumbrados a partir da descrição da vivência desses grupos humanos com o ambiente e com a biodiversidade ao longo do tempo até os dias atuais.

Para Diegues e Arruda (2001), as populações tradicionais são grupos culturalmente diferenciados que construíram, durante sua trajetória histórica, uma forma particular de lidar com a natureza e seus recursos. Ainda, consideram importantes a cooperação social entre seus membros, a adaptação a um meio ecológico específico e um grau de isolamento variável. Dayrell (1998) se refere à sociedade tradicional como camponesa, composta por agricultores, coletores extrativistas, garimpeiros artesanais e pescadores. Tal sociedade, segundo Toledo (1991), consome parte ou o todo do que adquire com o seu trabalho e com seu meio intelectual, com suas crenças e conhecimentos compartilhados socialmente. Entretanto, segundo esse autor, tradicional não quer dizer antigo, estático, mas um sistema cultural dinâmico, que se transforma e se renova.

A territorialidade é outra forte característica das populações tradicionais. Segundo Little (2004), a territorialidade é o esforço coletivo que um grupo social historicamente constrói ao ocupar, usar, controlar e desenvolver um sentimento de pertencimento a uma parcela de seu ambiente biofísico, que se converte em um território de uso comum. Para Saquet (2007), o território significa identidade, entendida como produto de interações recíprocas, de territorialidades, no âmbito das relações que acontecem entre a sociedade e a natureza (SAQUET, 2007). Numa outra perspectiva de análise, por meio de um diálogo entre a geografia, a ecologia humana e a ecologia comportamental, Malmberg (2019) propõe o conceito de territorialidade como um fenômeno manifestado pela delimitação e defesa de um espaço mais ou menos exclusivo ao qual um indivíduo ou grupo de seres humanos se vincula emocionalmente; espaço no qual seus limites são demarcados por estruturas materiais, imateriais e comportamentos que demonstram a aderência do grupo a este espaço.

Baseando-se em uma revisão sobre os conceitos de povos, populações e comunidades 
tradicionais trabalhados em diversos autores, dentre os quais Diegues e Arruda (2001) e nas experiências de pesquisa do Projeto "Opará: tradições, identidades, territorialidades $e$ mudanças entre populações rurais e ribeirinhas no Sertão Roseano”, Brandão (2012) atualiza o conceito de comunidade tradicional, incluindo a experiência da comunidade nos conflitos ambientais e na relação com as lógicas econômicas de mercado, como demonstramos a seguir:

[...] um grupo social local que desenvolve: [...] e) a atualização pela memória da historicidade de lutas e de resistências no passado e no presente para permanecerem no território ancestral; f) a experiência da vida em um território cercado e/ou ameaçado; g) estratégias atuais de acesso a direitos, a mercados de bens menos periféricos e à conservação ambiental (2012, p. 379).

O Norte de Minas abriga diversos povos e comunidades tradicionais, grupos que, historicamente, têm construído estratégias de luta para manutenção de seus territórios contra a invasão de projetos de "des-envolvimento". O termo des-envolvimento, como proposto por Viana (1999, p. 242-243), refere-se ao processo histórico de perda de envolvimento das comunidades tradicionais em relação a seu espaço, história, dignidade, conhecimentos e saberes. Tal processo ocasiona prejuízo à preservação ambiental e à cidadania. Essa dinâmica remonta ao império e chega até o Estado moderno, testemunhada por meio das lutas contra as fazendas, contra o agronegócio, contra a silvicultura, a mineração e, mais recentemente, contra as Unidades de Conservação.

A fim de compreender melhor essas populações em sua relação com o ambiente, é preciso compreender também a própria região norte-mineira. Segundo Dayrell (1998), topos de serra, planaltos e encostas, também chamadas de Gerais, dominadas pelos Cerrados, ocupam $63,4 \%$ da paisagem. A caatinga ocupa $12,9 \%$ e a mata seca, $7,2 \%$. As matas ciliares, veredas e pindaibais ocupam $3 \%$ do território e, no restante, o que corresponde a cerca de 14\%, ocorre o predomínio de vegetações transicionais de cerrados, florestas e caatingas.

Possui ainda uma rede hidrográfica composta de 1180 rios e córregos banhados por três bacias: a do Rio São Francisco, a do Rio Jequitinhonha e a do Rio Pardo. $\mathrm{Na}$ região, o principal bioma onde se encontram os povos e comunidades tradicionais é o Cerrado - o qual, de acordo com Barbosa e Nascimento (1990), vem sendo ocupado por populações humanas há pelo menos 11.000 anos. Considerado o segundo maior bioma brasileiro, corresponde a $21 \%$ do território nacional e é superado em área apenas pela Amazônia. Diferentes ecossistemas característicos do Brasil Central estão presentes no Cerrado, como savanas, matas, campos e matas ciliares (RIBEIRO; SANO; SILVA, 1981). Ao lado das matas ciliares há ainda variados habitat de campos úmidos, veredas, brejos e pindaíbas. No norte de Minas Gerais, especificamente, o Cerrado ainda sofre forte 
influência do bioma da Caatinga, ampliando a heterogeneidade dos recursos ecológicos nessa região. Com efeito, para Dayrell (1998), as formas transicionais de vegetação influenciaram a diversificação dos ambientes e ocasionaram o desenvolvimento de estratégias de acesso e uso dos diferentes habitats, favorecendo a complexa e rica sociobiodiversidade encontrada no Norte de Minas Gerais.

Desse modo, de maneira geral, podemos dividir as populações tradicionais dessa região, ainda na atualidade, de acordo com a paisagem em que vivem e com os recursos que utilizam, provenientes dessa paisagem (ANAYA et al., 2012; ANAYA; ESPÍRITO-SANTO, 2018; ARAÚJO, 2008; COSTA, 2011; DAYRELL et al., 2019; NOGUEIRA, 2009; RODRIGUES; THÉ, 2014). Os geraizeiros vivem nos gerais; veredeiros, nas veredas; ribeirinhos e vazanteiros vivem nas margens do Rio São Francisco; caatingueiros vivem nas Caatingas; quilombolas são os remanescentes de quilombos e os indígenas são pertencentes à etnia Xakriabá. Essas identidades autodenominadas são elaboradas pelos grupos a partir do contraste ou diferenças com os demais grupos com quem estabelecem relações sociais, como aborda Barth (2005).

Dayrell (1998) afirma que os gerais se referem, aos planaltos, encostas e vales das regiões dominadas pelos cerrados, com solos frequentemente ácidos e de baixa fertilidade. "Geraizeiros, como cultural e contrastivamente são assim denominados os habitantes dos gerais, desenvolveram a habilidade de cultivar às margens dos pequenos cursos d'água uma diversidade de culturas como a mandioca, cana, amendoim, feijões diversos, milho e arroz" (DAYRELL, 1998, p. 56). O sistema de produção de gado e suínos era do tipo "à solta" e, até por volta da década de 1970, era hegemônico o uso comunal das áreas de chapadas, tabuleiros e campinas. É ainda nessas áreas, denominadas genericamente como gerais, que essas comunidades tradicionais garantem sua subsistência por meio de atividades como a caça, a coleta de frutos diversos, a coleta e cultivo de plantas medicinais, o extrativismo de madeiras para diversos fins e de mel silvestre. "Os produtos que levam para o mercado - farinha de mandioca, goma, rapadura, aguardente, frutas nativas, plantas medicinais, artesanato - refletem o ambiente, o modo de vida, as possibilidades e potencialidades dos agroecossistemas onde vivem". (DAYRELL, 1998, p. 57).

Veredas são formações savânicas caracterizadas por campos úmidos permanentes, colonizados por populações de palmeiras da espécie Mauritia flexuosa e algumas espécies arbustivas (RIBEIRO; WALTER, 1998). As "gentes das veredas", ou veredeiros, segundo Costa (2011), são identificadas a partir do contraste entre esses grupos e os outros que vivem na mesma área geográfica: os campineiros e chapadeiros. Os veredeiros do Alto-Médio São Francisco fazem criação de gado, são agricultores, extrativistas, além de praticarem a caça e a pesca (COSTA, 2011). 
Segundo Jacinto (1998), a base econômica dos povos veredeiros está principalmente na agricultura do feijão, mandioca, milho e arroz, o qual é cultivado através da técnica de "esgoto", que são canais estreitos abertos a partir das veredas para irrigação do cultivo. Ainda, segundo Rodrigues e Thé (2014) possuem uma relação específica com os recursos hídricos, compreendidos como bem comum que não podem ser apropriados de forma privada.

Luz de Oliveira (2005), em sua pesquisa sobre identidade e dinâmica de vazanteiros do norte de Minas Gerais, se refere a esse grupo como povos habitantes das áreas inundáveis da Bacia do São Francisco, incluindo as Ilhas, e que se caracterizam pela prática da agricultura de "vazante" (cultivos realizados em sedimentos depositados nas margens planas do São Francisco, conhecidas como "lameiros"), da agricultura de "sequeiro" (plantio nas "terras altas" ou "barrancos" nas margens do rio), da criação animal e do extrativismo de frutos e madeira.

Os quilombolas, ou remanescentes de quilombo, formam um dos povos tradicionais de maior incidência no norte de Minas. Esse grupo tem origem nas margens dos ribeirões, lagoas e rios que compõem a bacia do rio Verde Grande, com relações com povoações ao longo do rio São Francisco (COSTA, 2006). Muitas das tradições de produção e extrativismo das demais comunidades tradicionais residentes ao longo do São Francisco citadas anteriormente têm origem na cultura afro-brasileira e indígena.
A única população indígena remanescente no norte de Minas Gerais pertence à etnia Xakriabá, originária da população dos Tapuias, correspondentes aos grupos que compõem o grupo linguístico Macro-Jê, apontados como os principais habitantes do Cerrado no período précolonial (RIBEIRO, 2005). O povo Xakriabá, hoje representado por 6.442 indivíduos, se encontra entre o município de São João das Missões e Itacarambi, numa região de transição entre o cerrado e a caatinga (GOMES, 1998). O sistema de produção Xakriabá se estabeleceu nos moldes da produção regional sertaneja, cabocla. Entretanto, com a diminuição do acesso ao território indígena original, houve mudança nas formas produtivas familiares e comunitárias. A caça e a pesca, por exemplo, foram impactadas devido à redução do território a áreas de pastagens, encostas e chapadas, levando os indígenas a obterem produtos essenciais mediante trocas monetárias (LUZ DE OLIVEIRA, 2005; SANTOS, 1997). Apesar disso, ainda podem ser verificadas algumas práticas e crenças próprias de sua cultura.

Esses grupos são alguns exemplos de comunidades tradicionais existentes apenas no Norte de Minas Gerais. Há muitas outras comunidades tradicionais, com suas diversas formas de territorialidade, ao redor do Brasil, por toda a costa atlântica, por todo interior do Norte ao Sul do território nacional. Para que conheçamos tanto a biodiversidade conservada e manejada por essas populações, como também toda a riqueza cultural produzida por elas, é 
fundamental que políticas adequadas de apoio a esses grupos sejam implementadas a fim de garantir o domínio, o acesso e o uso de seus lugares de vida, onde seus saberes e práticas, seus mitos, seus ritos e sua sociobiodiversidade são reproduzidos desde tempos passados.

Segundo Medeiros, ao se analisar de forma mais ampla a presença das pessoas nos diversos ecossistemas existentes, deve-se levar em conta "a rede informacional que é gerada e/ou utilizada pela espécie humana, que traça diferentes cursos históricos a partir de suas decisões” (2010, p. 12). Para Marques, “esta rede informacional é constituída não somente pelo conhecimento gerado pelas interações entre os humanos e o meio, mas igualmente é modulada pelos sentimentos, crenças e comportamentos próprios do homem" (2001, p. 23). Descrever essa história ambiental das comunidades tradicionais é um dos principais objetivos das etnociências, como etnobiologia e etnoecologia.

A história ambiental de comunidades tradicionais remonta o processo adaptativo ao longo do tempo entre os grupos de humanos e a natureza, com a qual interagem num determinado espaço. Tal interação pode ter por objetivo suprir a alimentação, o instrumental de trabalho, o abrigo ou moradia, entre outros aspectos com importância nutritiva, econômica ou material, bem como pode suprir também aspectos de importância imaterial, ritualística ou sobrenatural. Conhecer essa história ambiental, segundo Medeiros (2010), é de fundamental importância para qualquer sociedade, pois 0 acesso a essa diversidade de memórias comunitárias possibilita uma reflexão sobre o processo de conhecimento e utilização dos recursos biológicos entre tempos, entre o passado e o presente.

Sabe-se que povos e comunidades tradicionais rurais têm imensa importância na conservação da biodiversidade, não só no Brasil como ao redor do mundo (GÓMEZ-POMPA; KAUS, 1992). Estudos em etnoecologia contribuem para a valorização de bioculturas, representadas no Norte de Minas por esse rico mosaico de comunidades rurais e seus territórios tradicionais, pois elas apontam para melhores opções de acesso e uso da natureza em contraposição às que têm sido disseminadas e ampliadas pelo modelo hegemônico de sociedade urbano-agro-industrial (DUQUE-BRASIL et al., 2019). Toledo e Barreira-Bassols (2009) denominam a própria etnoecologia como "a valorização dos conhecimentos milenares sobre a natureza dos povos indígenas e rurais do planeta" (p. 31), no intuito resgatar o que a ciência moderna tornou invisível, isto é "as ecologias das 7.000 culturas indígenas que resistem à expansão do mundo industrial e que sustentam os ecossistemas planetários" (TOLEDO; BARREIRA-BASSOLS, 2009). Como apontou Posey (1987), aqueles que estudam o conhecimento tradicional e tentam encontrar suas aplicações modernas não propõem que o mundo reverta ao estado de existência tribal. Existem opções para a sobrevivência da humanidade na biosfera e muitas delas estão 
codificadas nas "realidades" dos povos e comunidades tradicionais.

\section{Povos e comunidades tradicionais} e a luta por seus territórios

Os povos e as comunidades tradicionais brasileiras enfrentam diversos desafios, principalmente a dificuldade de reconhecimento de seus direitos identitários, culturais e territoriais. Sofrem discriminação por seu movimento de resistência para manter os vínculos com suas paisagens, para manterem seus modos de vida - e os processos sociais, econômicos e culturais que os compõem - num determinado espaço geográfico, seu território (ANAYA; ESPIRITO-SANTO, 2018; ALMEIDA; MARIN, 2012; PIMENTEL; RIBEIRO, 2016). Desafiam o modelo de desenvolvimento por crescimento econômico a partir dessa resistência, a qual pode ser expressa, na prática, de diversas maneiras, desde o isolamento de suas comunida des até a luta direta. Esse modelo, que é aplicado por governos brasileiros em todas as suas esferas (municipais, estaduais, federais), apresenta uma lógica predatória de apropriação dos recursos materiais e naturais e a expulsão - ou até mesmo o "etnogenocídio" - de qualquer modo de vida que conteste a hegemonia ideológica e política desse modelo de desenvolvimento (ZHOURI; LASCHEFSKI, 2010.

Muitos enfrentamentos, ou conflitos ambientais, contra a expansão desse tipo de desenvolvimento sobre territórios tradicionais têm sido descritos envolvendo as comunidades norte-mineiras apresentadas no início deste texto. Entendemos que os conflitos ambientais são aqueles que ocorrem "quando há um desacordo no interior do arranjo espacial de atividades de uma localidade, região ou país: a continuidade de um tipo de ocupação do território vê-se ameaçada pela maneira como outras atividades, espacialmente conexas, são desenvolvidas" (ZHOURI; OLIVEIRA, 2005, p. 62). Segundo trabalhos como Luz de Oliveira (2005), Anaya et al. (2012) e Araújo (2008), as comunidades vazanteiras e quilombolas do Rio São Francisco têm sobrevivido em meio aos processos sócio-históricos de encurralamento e expropriação de suas famílias, em meio à hegemonia da política de Estado de apoio à formação de latifúndios desde o século XIX e a grandes projetos de irrigação do final do século $\mathrm{XX}$ até os tempos atuais. Mesmo assim, essas populações têm se adaptado ao longo do tempo, tanto nos aspectos sociais como ecológicos, desenvolvendo uma relação estratégica de convivência com o ambiente e as margens do Rio São Francisco, em tempos de seca ou de enchentes. Assim, mantêm modos de uso e manejo da terra e do rio desde os tempos mais remotos com técnicas ancestrais de produção, de origem indígena e africana.

Essas comunidades ainda vivem o desafio de se contrapor ao Estado na política ambiental de proteção da biodiversidade brasileira a partir da criação de Unidades de Conservação de 
Proteção Integral. $\mathrm{O}$ debate sobre sua implantação como opção de gestão ambiental para conservação de biodiversidade já se desenvolve desde meados da década de 1990. Ainda permanece, porém, sem grandes inovações, mesmo com a criação das Reservas Extrativistas e das Reservas de Desenvolvimento Sustentável como opção para se conjugar os interesses de proteção ambiental e de uso sustentável da natureza, já que tais reservas ainda são minoria ou existem apenas sob a forma de decretos, sem recursos financeiros destinados a sua real implantação (CARDOSO, 2008; DE FIGUEIREDO; BARROS, 2016).

Os territórios tradicionais se formam historicamente a partir de um processo que podemos denominar "territorialização". A territorialização pressupõe apropriação e dominação simbólica e material do espaço. Dessa forma, as condições apresentadas pelo espaço (clima, solo, disponibilidade de recursos como água, terra de cultura e minérios, por exemplo) determinam as ações humanas de controle e poder que conduzem à forma particular de cada sociedade interagir sobre esse espaço feito território. Tais formas de apropriação social do território estão diretamente relacionadas a questões culturais de uso e significação do espaço.

Há diversos conflitos ambientais no Brasil que forçam a "desterritorialização" dos povos e comunidades tradicionais. Empreendimentos hidroelétricos, mineração, expansão urbana, projetos e empreendimentos de reprodução e concentração do capital e até mesmo a criação de
Unidades de Conservação provocam a expulsão de milhares de pessoas de seus lugares de vida ao redor do Brasil. No contexto específico do Norte de Minas Gerais, a inserção dessa região no escopo da expansão capitalista deu início a um período de expropriação, desestruturação e reestruturação dos modos de vida tradicionais a partir do final da década de 1970, quando a vegetação nativa do cerrado nas chapadas foi substituída por maciços de Eucaliptos e Pinus. Todavia, o ciclo de degradação e homogeneização socioambiental pela expansão da matriz capitalista de desenvolvimento não solapou a lógica não capitalista que imperava na região, embora tenha se tornado hegemônico (COSTA, 2006). Dessa forma, o modo de vida das famílias camponesas e dos povos e comunidades tradicionais do Norte de Minas ainda sobrevive, às vezes em "complementaridade e, às vezes, em oposição às lógicas construtoras de territorialidades e espaços sociais distintos" (COSTA, 2006, p.28).

\section{A contribuição da Etnoecologia aos direitos territoriais e à conservação} da sociobiodiversidade

Nas décadas de 1970 e 1980, consolidam-se movimentos ambientalistas, marcando os debates sobre a questão ambiental e colocando em xeque um modelo de desenvolvimento que se espalhou pelo mundo, embalado pela globalização. Foi quando, nos anos de 1980, se 
consolidaram a noção de uso sustentável dos recursos naturais e o reconhecimento da existência dos "povos das florestas", "isto é, os grupos indígenas, ribeirinhos, seringueiros e demais grupos tradicionais, que se tornaram protagonistas na história de superação da dicotomia sociedade-natureza e da promoção do desenvolvimento sustentável” (ZHOURI; LASCHEFSKI, 2010, p.12). A partir desse momento, ganha força um movimento que busca orientar políticas ambientais que levem em consideração a diversidade sociocultural.

Também nesse período se iniciam trabalhos históricos em etnoecologia e etnobiologia no Brasil, podendo-se destacar os trabalhos de Posey (1987), Chernela (1985) e Cordell (1989), entre outros. Esses trabalhos apresentaram resultados demonstrando que o manejo dos ecossistemas por comunidades tradicionais se fundamenta em um conjunto de crenças e saberes acerca do uso dos recursos naturais, fundado nas tradições culturais e na vivência empírica do ambiente próximo. Comunidades ribeirinhas e vazanteiras do Médio São Francisco em Minas Gerais, por exemplo, dependem diretamente das variações dos ciclos ambientais e da bioecologia dos recursos naturais. Mantêm uma associação íntima com os ecossistemas aquáticos e terrestres da Bacia do Rio São Francisco, desenvolvendo conhecimentos e compreensões imprescindíveis para a sua sobrevivência, seja pelo agroextrativismo, seja pela agricultura de vazante, seja pela pesca (THÉ, 2003). A etnoecologia é essencialmente o estudo desse saber acumulado, das conceituações desenvolvidas por qualquer sociedade humana a respeito da natureza e dos diferentes usos e formas de manejo dos recursos naturais (ALBUQUERQUE, 2014; MARQUES, 1995; TOLEDO, 1992).

É desejável, portanto, que as proposições de gestão ambiental e planejamento territorial incorporem os saberes e as práticas tradicionais, além de garantir que os usuários, como pescadores artesanais, comunidades tradicionais extrativistas, entre outras, participem ativamente dos processos decisórios e normativos sobre o uso recursos naturais. Berkes et al. (2001) denominaram este procedimento como manejo tradicional comunitário ("community based managament"), um processo de manejo de recursos, dinâmico ao longo do tempo, envolvendo aspectos de democratização, "empoderamento" social, equitabilidade de poder e descentralização.

Os povos e as comunidades tradicionais do Norte de Minas Gerais têm demonstrado um "universo" de conhecimentos, práticas de manejo e valores éticos que têm contribuído para a conservação de recursos naturais ameaçados, como os pertencentes ao bioma do Cerrado, dos quais restam apenas $20 \%$ em suas condições originais. Pescadores, vazanteiros, geraizeiros, entre outros, possuem uma compreensão própria dos comportamentos ecológicos, migratórios e alimentares da fauna silvestre, que muitas vezes supera o detalhamento científico sobre tais comportamentos. Ainda, discernem com acuidade 
os habitats, as áreas de vida e os períodos reprodutivos, entre outros aspectos da biologia dos animais terrestres e aquáticos. Utilizam a fauna com propósitos alimentares, medicinais, comerciais e até ritualísticos. Quanto aos conhecimentos botânicos, são costumeiramente mais abrangentes do que os conhecimentos sobre a fauna. O conhecimento tradicional refere-se inclusive ao melhoramento genético de espécies consideradas de maior importância, principalmente das cultivadas para a alimentação ou de maior valor econômico. Compreendem o funcionamento dos ciclos hidrológicos dos rios e das épocas específicas de plantio e colheita adequadas para a região semiárida, na qual se inclui o Norte de Minas Gerais (ARAÚJO, 2012; ANAYA et al., 2012; DAYRELL, 1998; LUZ DE OLIVEIRA, 2005; THÉ, 2003).

Essas comunidades têm denunciado, através de movimentos em rede, as ameaças à sociobiodiversidade regional, seja pela expansão agrícola e minerária; seja pela contaminação “acidental” (na maioria das vezes, proposital e criminosa) de cultivos orgânicos por transgênicos, exigindo-se o pagamento da propriedade intelectual sobre os recursos genéticos para as grandes empresas produtoras de sementes; seja pelas mudanças climáticas, explicitadas pelo prolongamento da estação seca e com o consequente aumento do déficit hídrico no semiárido brasileiro. Todas essas ameaças estão na agenda de discussão para políticas públicas de proteção dos patrimônios "bioculturais" do Cerrado e de outros biomas brasileiros. As comunidades também apresentam críticas às políticas de desenvolvimento implementadas pelo Estado brasileiro, focadas principalmente no mundo rural, para a expansão do agronegócio, da silvicultura e da produção de energia por meio da construção de barragens hidrelétricas e do plantio de cana-de-açúcar e soja para o biodiesel, as quais ameaçam a sobrevivência futura de suas identidades, de seus territórios e seus modos de vida tradicionais (COMBATE RACISMO AMBIENTAL, 2013, CARTA..., 2015).

Todo esse conjunto de conhecimento, práticas e crenças acumulado pelas populações tradicionais vem questionar a manutenção do modelo de gestão dos recursos naturais no Brasil, centralizado nas mãos do Estado, com pouca ou nenhuma participação das comunidades nos planos de manejo e proteção dos diversos ecossistemas. Mesmo quando suas propostas parecem ir ao encontro de políticas já constituídas pelo Estado em formas de leis e programas, a efetiva implementação é um grande desafio. Exemplo disso é a luta pela criação de Reservas Extrativistas e Reservas de Desenvolvimento Sustentável no Cerrado. Há oito reservas sendo pleiteadas há cerca de 10 anos no Norte de Minas Gerais, e apenas uma foi criada pelo órgão responsável no Brasil, o ICMBio (Instituto Chico Mendes de Conservação da Biodiversidade), no ano de 2014, às vésperas das eleições presidenciais: a Reserva de 
Desenvolvimento Sustentável Nascentes Geraizeiras (BRASIL, 2014).

\section{Considerações Finais}

Em um país com grande ocorrência de disputas de direitos sobre recursos naturais e casos de injustiça ambiental envolvendo comunidades rurais tradicionais, é patente que propostas de desenvolvimento, centradas no modelo por crescimento econômico, coloquem em risco a capacidade de resiliência dos sistemas socioecológicos, isto é, sua capacidade de suportar distúrbios ou de se adaptar, após a ocorrência destes, para novas condições de estabilidade, como mudanças climáticas, crises econômicas, degradação ambiental pela implantação de grandes projetos econômicos como usinas hidroelétricas, irrigação, mineração, entre outros. Além dos impactos econômicos, culturais e ecológicos sobre os povos e seus territórios tradicionais, acirram-se conflitos, principalmente entre comunidades e instituições governamentais, impondo-se um enorme desafio à gestão ambiental.

Entender como povos e comunidades tradicionais se relacionam com seu ambiente de vida, seja produzindo conceituações e "etnotaxonomias", seja manejando a diversidade biológica por meio de regras locais que determinam os modos de acesso e uso da natureza, pode e deve contribuir para o desenvolvimento de políticas públicas ambientais mais justas e equitativas para as populações tradicionais e para a conservação da sociobiodiversidade. Essa contribuição seria a materialização da manutenção de territórios tradicionais e de diferentes bioculturas, bem como a resolução de diversos conflitos ambientais no Norte de Minas, em outras áreas do Brasil e do mundo.

É imprescindível que haja mudança de valores e posturas para o reconhecimento das diversas culturas e saberes ecológicos na gestão ambiental brasileira. Isto significará também estender para distintos grupos tradicionais a possibilidade de decisão dos rumos do modelo de desenvolvimento a se seguir, assegurando direitos a cidadãos que já optaram há tempos por outros modelos, com enfoques na comunidade, na história ambiental local, na justiça e, principalmente, na sustentabilidade da sociobiodiversidade.

\section{Agradecimentos}

Agradeço aos professores, pesquisadores e discentes do Núcleo Interdisciplinar de Investigação socioambiental - NIISA e do Laboratório de Educação Ambiental e Ecologia Humana - LEAH da Unimontes, pelo convívio e a parceria em pesquisas desde 2012. Agradeço à FAPEMIG pela concessão de Bolsa de Incentivo a Pesquisa - Bolsa BIP, entre os anos de 2016, 2017 e 2018.

\section{Referências}


ANAYA, F.; ESPÍRITO-SANTO, M. Protected areas and territorial exclusion of traditional communities: analyzing the social impacts of environmental compensation strategies in Brazil. Ecology and Society, v. 23, n. 1, 2018. https://doi.org/10.5751/ES-09850-230108/

ANAYA, F.; ZHOURI, A.; BARBOSA, R. S. Conflitos ambientais territoriais no Norte de Minas: a resistência das comunidades vazanteiras frente à expropriação dos parques ambientais. In: ALMEIDA, A. W. B. et al. (Org.). Quilombolas: reivindicações e judicialização dos conflitos. Manaus: UEA, 2012. p. 75-116. (Cadernos de debates nova cartografia social, v. 1, n. 3). Disponível em: $<$ http://novacartografiasocial.com.br>.

ALBUQUERQUE, U. P. Introdução à etnobiologia. Recife, PE: NUPEEA, 2014.

ALMEIDA, A. W. B. D. D.; MARIN, R. E. A.; Apresentação. In: ALMEIDA, A. W. B. et al. (Org.). Cadernos de Debates Nova Cartografia Social: Quilombolas: reivindicações e judicialização de conflitos. Manaus: UEA Edições, 2012. Disponível em: $<$ http://novacartografiasocial.com.br/download/0 3 -quilombolas-reivindicacoes-e-judicializacaodos-conflitos/>.

ARAUJO, E. C. Populações negras vazanteiras do rio São Francisco e suas dinâmicas territoriais frente ao encurralamento. 2008. Trabalho apresentado ao $1^{\circ}$ Congresso de Desenvolvimento Social: globalização do regional e regionalização do global, Montes Claros, MG, 2008.

BARBOSA, R. S., NASCIMENTO, I. V. Processos culturais associados à vegetação. In: Pinto, M. N. (Org.). Cerrado: caracterização, ocupação e perspectivas. Brasília, DF: Editora Universidade de Brasília, 1990. p. 147-162.

BARTH, F. Etnicidade e o conceito de cultura. Revista Antropolítica, Niterói, n. 19, p. 15-30, 2005.

BERQUE, A. Paisagem-marca, paisagem-matriz: elementos da problemática para uma geografia cultural. Geografia cultural: uma antologia, v. $1, \quad$ p. $239-243, \quad 2012$. https://doi.org/10.7476/9788575114384/>.

BERKES, F. et al. Managing small-scale fisheries: alternative directions and methods. Ottawa: International Development Research Centre, 2001. Disponível em: $<$ https://www.idrc.ca/en/book/managing-small- scale-fisheries-alternative-directions-andmethods $>$.

BRANDÃO, C. R. Comunidades tradicionais do norte de Minas Gerais. In: COSTA, J. B. A.; LUZ DE OLIVEIRA, C. (Org.). Cerrado, Gerais, Sertão: comunidades tradicionais nos sertões roseanos. 1. ed. São Paulo: Intermeios, 2012. v. 1. p. 31-46.

BRASIL. Decreto de 13 de outubro de 2014. Cria a Reserva de Desenvolvimento Sustentável Nascentes Geraizeiras, localizada nos Municípios de Montezuma, Rio Pardo de Minas e Vargem Grande do Rio Pardo, Estado de Minas Gerais. Diário Oficial [da] República Federativa do Brasil, Poder Executivo, Brasília, DF, 14 out. 2014. Seção 1, p. 9-14. Disponível em: <http://www.planalto.gov.br/CCIVIL_03/_Ato20 11-2014/2014/Dsn/Dsn14016.htm>. Acesso em: 16 de setembro de 2016.

CARDOSO, T. A. A construção da gestão compartilhada da Reserva Extrativista do Mandira, Cananéia, SP. 2008. 203 p. Tese (Doutorado em Ciências)-Universidade Federal de São Carlos, São Carlos, SP, 2008.

CARTA do II Encontro da agrobiodiversidade do semiárido mineiro. [S.l.: s.n.], [2015]. Disponível

em: http://www.caa.org.br/media/publicacoes/CART A_DO_II_ENCONTRO_DA_AGROBIO_SEMI\% C3\%81RIDO_MINEIRO_final_2.pdf. Acesso em: 18 de outubro de 2016 .

CHERNELA, J. M. Indigenous fishing in the neotropics: the tukanoan uanano of the blackwater Uaupes river Basin in Brazil and Colombia. Interciencia, [Caracas], v. 10, n. 2, p. $79-86,1985$.

COMBATE RACISMO AMBIENTAL. Carta do I Encontro de agrobiodiversidade dos povos do semiárido mineiro: "para continuarmos vivendo precisamos das águas renascidas, de nossas terras retomadas, das sementes da gente!". [S.l.], 2013. Blog. Disponível em: $<$ http://racismoambiental.net.br/?p=124119>. Acesso em: 18 de outubro de 2016.

CORDELL, J. Marginalidade social e apropriação territorial marítima na Bahia. In: DIEGUES, A. C.; MOREIRA, A. C. C. (Org.). Espaços e recursos naturais de uso comum. São Paulo: NUPAUB, USP, 2001. p. 139-162.

COSTA, J. B. A. Cultura, natureza e populações tradicionais: o norte de Minas como síntese da 
nação brasileira. Revista Verde Grande, Montes Claros, MG, v. 1, n. 3, p.8-45, 2006.

Tempo reversivo e espaço transfigurado: etnocídio nas veredas do sertão. Campoterritório: revista de geografia agrária, [Uberlândia], v. 6, n. 11, p. 161-193, 2011.

DAYRELL, C. A. Geraizeiros e biodiversidade no norte de Minas: a contribuição da agroecologia e da etnoecologia nos estudos dos agroecossistemas tradicionais. 1998. $192 \mathrm{f}$. Dissertação (Mestrado em Agroecologia y Desarrollo Rural Sostenible)-Universidade Internacional de Andalucia, [S.l.], 1998.

Montes Claros: Centro de Agricultura Alternativa para Learning Journey in Inclusive Land Governance. Norte de Minas, 2016. 63 slides, color. Acompanha texto. Slides produzidos para evento realizado de 02 a 07 de maio de 2016.

DAYRELL, C. A. et al. "Auto demarcacão e gestão do território tradicional dos Vazanteiros do Pau Preto, MG". In: Coleção Povos e Comunidades Tradicionais V.3. Sistemas Agrícolas Tradicionais no Brasil. Jane Simoni Eidt; Consolacion Udry. (Org.). Embrapa: Brasília-DF. 2019. p. 153-166.

DE FIGUEIREDO, R. A. A.; BARROS, F. B. Sabedorias, cosmologias e estratégias de caçadores numa unidade de conservação da Amazônia. Desenvolvimento e Ambiente, v. 36, 2016. http://dx.doi.org/10.5380/dma.v36i0.43351

DIEGUES, A. C. (Org.). Etnoconservação: novos rumos para conservação da natureza nos trópicos. São Paulo: HUCITEC, 2000. Disponível em: <http://nupaub.fflch.usp.br/sites/nupaub.fflch.u sp.br/files/Etnoconservacao\%20livro\%20complet o.pdf>.

DIEGUES, A. C. A ecologia política das grandes ONGs transnacionais conservacionistas. São Paulo: NUPAUB, USP, 2008.

DIEGUES, A. C.; ARRUDA, R. S. V. (Org.). Saberes tradicionais e biodiversidade no Brasil. Brasília, DF: Ministério do Meio Ambiente; São Paulo: USP, 2001. (Biodiversidade, 4).

DUQUE-BRASIL, R. et al. Etnoecologia e retomada de territórios tradicionais Vazanteiros no médio rio São Francisco, norte de Minas Gerais. Revista Ouricuri, v. 3, n. 2, p. 089-105, 2019 ; Disponível
$<$ https://www.revistas.uneb.br/index.php/ouricu ri/article/view/6423/4058>.

GOMES, L. J. Extrativismo e comercialização da fava-d'anta (Dimorphandra sp.): um estudo de caso na região de cerrado de Minas Gerais. 1998. 158 p. Dissertação (Mestrado em Engenharia Florestal) - Universidade Federal de Lavras, Lavras, MG, 1998.

GÓMEZ-POMPA, A.; KAUS, A. Taming the wilderness myth. BioScience, [S.1.], v. 42, n. 4, p. 271-279, 1992. https://doi.org/10.2307/1311675

JACINTO, A. B. M. Afluentes de memória: itinerários, taperas e histórias no Parque Nacional Grande Sertão Veredas. 1998. 211 f. Dissertação (Mestrado em Antropologia) Universidade Estadual de Campinas, Campinas, SP, 1998.

LITTLE, P. Territórios sociais e povos tradicionais no Brasil: por uma antropologia da territorialidade. In: ANUÁRIO Antropológico 2002/2003. Rio de Janeiro: Tempo Brasileiro, 2004. p. 251-290. Disponível em: <http://www.dan.unb.br/images/pdf/anuario_an tropologico/Separatas\%202002-2003/20022003_paullittle.pdf $>$.

LUZ DE OLIVEIRA, C. Vazanteiros do rio São Francisco: um estudo sobre populações tradicionais e territorialidade no Norte de Minas Gerais. 2005. 134 f. Dissertação (Mestrado em Sociologia)-Universidade Federal de Minas Gerais, Belo Horizonte, 2005.

MALMBERG, T. Human Territoriality: Survey on the Behavioural Territories in Man with Preliminary Analysis and Discussion of Meaning. Walter de Gruyter GmbH \& Co KG, 2019.

MARQUES, J. G. W. Pescando pescadores: etnoecologia abrangente no baixo São Francisco alagoano. São Paulo: NUPAUB, USP, 1995.

Pescando pescadores: ciência e etnociência em uma perspectiva ecológica. São Paulo: NUPAUB-USP, 2001.

- O olhar (des)multiplicado: o papel do interdisciplinar e do qualitativo na pesquisa etnobiológica e etnoecológica. In: AMOROZO, M. C. M.; MING, L. C.; SILVA, S. P. (Ed.). Métodos de coleta e análise de dados em etnobiologia, etnoecologia e disciplinas correlatas. Rio Claro, SP: UNESP, 2002. p. 3146.

MMA (Ministério do Meio Ambiente) - SNUC (Sistema Nacional de Unidades de Conservação). 
2000. MMA, SNUC, Brasília. Disponível em: <https://www.mma.gov.br/estruturas/202/_arqu ivos/lei_n_9985_2000_snuc_sist_nacional_de_u nidades_de_conservao_202.pdf $>$.

MEDEIROS, M. F. T. A interface entre a história, a etnobiologia e a etnoecologia. In: MEDEIROS, M. F. T. (Org.). Aspectos históricos na pesquisa etnobiológica. Recife: NUPEEA, 2010.

PIMENTEL, M. A. S.; RIBEIRO, W. C. Populações tradicionais e conflitos em áreas protegidas. GEOUSP: Espaço E Tempo (Online), v. 20, n. 2, p. 224-237, 2016. https://doi.org/10.11606/issn.2179-

0892.geousp.2016.122692

NOGUEIRA, M. C. R. Gerais a dentro e a fora: identidade $e$ territorialidade entre Geraizeiros do norte de Minas Gerais. 2009. 233 f. 2009. Tese de Doutorado. Tese (Doutorado)-Curso de Antropologia Social, Departamento de Departamento de Antropologia, Universidade de Brasília, Brasília.

POSEY, D. A. Introdução - Etnobiologia: teoria e prática. In: RIBEIRO, B. G. (Coord.). Suma etnológica brasileira. Etnobiologia. Petrópolis, RJ: Vozes, 1987. v.1.

RIBEIRO, J. F.; SANO, S. M.; SILVA, J. A. Chave preliminar de identificação dos tipos fisionômicos da vegetação do Cerrado. In: CONGRESSO NACIONAL DE BOTÂNICA, 32., 1981, Teresina. Anais... Teresina: Sociedade Botânica do Brasil, 1981. p. 124-133.

RIBEIRO J. F.; WALTER, B. M. T. Fitofisionomias do bioma Cerrado. In: SANO S. M.; ALMEIDA S. P. (Org.). Cerrado: ambiente e flora. Brasília, DF: Embrapa Cerrados, 1998. p. 87-166.

RIBEIRO, R. F. Florestas anãs do sertão: o cerrado na história de Minas Gerais. Belo Horizonte: Autêntica, 2005.

RODRIGUES, L. R.; THE, A. P. G. Veredas, oásis do Sertão: conflito ambiental na apropriação das águas em Botumirim-MG. Soc. nat. [online]. 2014, vol. 26, n. 1 pp. 25-36. Disponível em: http://www.seer.ufu.br/index.php/sociedadenatu reza/article/view/17750

SANTOS, A. F. M. Do terreno dos caboclos do Sr. São João à terra indígena Xakriabá: as circunstâncias da formação de um povo. Um estudo sobre a construção social de fronteiras. 1997. 350 f. Dissertação (Mestrado em Antropologia) - Universidade de Brasília, Brasília, DF, 1997.
SAQUET, M. A. Abordagens e concepções de território. São Paulo: Expressão Popular, 2007.

SATO, M. Biorregionalismo: a educação ambiental tecida pelas teorias biorregionais. Encontros e caminhos: formação de educadoras (es) ambientais e coletivos educadores. Brasília: MMA, p. 39-46, 2005.

THÉ, A. P. G. Conhecimento ecológico, regras de uso e manejo local dos recursos naturais na pesca do alto-médio São Francisco, MG. 213 f. Tese (Doutorado em Ciências). Programa de Pós-Graduação em Ecologia e Recursos Naturais. Universidade Federal de São Carlos, São Carlos, SP, 2003. Disponível em: <https://repositorio.ufscar.br/handle/ufscar/177 9? show $=$ full $>$.

THÉ, A. P. G.; NORDI, N. Common Property Resource System in a Fishery of the Sao Francisco River, Minas Gerias, Brazil. Human Ecology Review, v. 13, n. 1, p. 1, 2006. Disponível em: <http://ww.w.humanecologyreview.org/pastissu es/her131/thenordi.pdf>.

THÉ, A. P. G. et al. "Pescar pescadores": fortalecimiento de la organización comunitaria para el manejo participativo de la pesca en el río San Francisco, Brasil. In: PINEDO D.; SORIA, C. (Ed.). El manejo de las pesquerías em ríos tropicales de Sudamérica. Bogotá, Colômbia: Mayol, 2008. p. 333-354. Disponível em: https://prd-

idrc.azureedge.net/sites/default/files/openebook s/420-8/\#page_333.

TOLEDO, V. M. El juego de la supervivencia: un manual para la investigación etnoecológica en Latinoamérica. [Santiago, Chile]: Consorcio Latinoamericano sobre Agroecología y Desarrollo, 1991.

. What is ethnoecology? Origins, scope and implications of a rising discipline. Etnoecológica, [Oaxaca, México], v. 1, n. 1, p. 5-21, abr. 1992.

TOLEDO, V.M.; BARRERA-BASSOLS, N. A etnoecologia: uma ciência pós-normal que estuda as sabedorias tradicionais. Desenvolvimento e Meio Ambiente, v. 20, 2009. http://dx.doi.org/10.5380/dma.v20i0.14519.

VIANA, V. M. Envolvimento sustentável e conservação das florestas brasileiras. Revista Ambiente e Sociedade, Campinas, n. 5, p. 241244, dez. 1999. Disponível em: <http://www.scielo.br/pdf/asoc/n5/n5a21.pdf>. 
ZHOURI, A.; OLIVEIRA, R. Paisagens industriais e desterritorialização de populações locais: conflitos socioambientais em projetos hidrelétricos. In: ZHOURI, A.; LASCHEFSKI, K.; PEREIRA, D. B. (Org.). A insustentável leveza da política ambiental. Belo Horizonte: Autêntica, 2005. p. 49-64.

ZHOURI, A.; LASCHEFSKI, K. Conflitos ambientais. In: ZHOURI, A.; LASCHEFSKI, K. (Org.). Desenvolvimento e conflitos ambientais. Belo Horizonte: UFMG, 2010. p.11-34. https://doi.org/10.7476/9788542303063 